\title{
Interaction between a bubble plume and the near field in a stratified lake
}

\author{
D. F. McGinnis, ${ }^{1,2}$ A. Lorke, ${ }^{3}$ A. Wüest, ${ }^{3}$ A. Stöckli, ${ }^{4}$ and J. C. Little ${ }^{1}$ \\ Received 20 January 2004; revised 7 May 2004; accepted 1 July 2004; published 20 October 2004.
}

[1] A steady state bubble-plume model is evaluated using full-scale temperature, salinity, and dissolved oxygen data collected in a Swiss lake. The data revealed a plume-generated near-field environment that differed significantly from the ambient far-field water column properties. A near-field torus of reduced stratification developed around the plume, the extent of which is on the same lateral scale as the horizontal dislocations generated by persistent first-mode seiching. The plume fallback water was found to penetrate much deeper than expected, thereby maintaining reduced vertical gradients in the near-field torus. The plume entrains a portion of the fallback water leading to short-circuiting, which generates a complex plume-lake interaction and reduces far-field downwelling relative to the upward plume flow. As the integral plume model incorporates the entrainment hypothesis, it is highly sensitive to the near-field environmental conditions. After identifying appropriate near-field boundary conditions the plume model predictions agree well with the field observations. INDEX TERMS: 4568 Oceanography: Physical: Turbulence, diffusion, and mixing processes; 1845 Hydrology: Limnology; 1857 Hydrology: Reservoirs (surface); 1871 Hydrology: Surface water quality; KEYWORDS: aeration, bubble plume, buoyancy, hypolimnion, oxygen transfer, reservoir

Citation: McGinnis, D. F., A. Lorke, A. Wüest, A. Stöckli, and J. C. Little (2004), Interaction between a bubble plume and the near field in a stratified lake, Water Resour. Res., 40, W10206, doi:10.1029/2004WR003038.

\section{Introduction}

[2] Excess phosphorous loading in lakes and reservoirs increases the content of organic matter, which, through decomposition, increases oxygen demand. Many eutrophic lakes do not contain sufficient hypolimnetic dissolved oxygen (DO) to meet this demand during the stratified season and become anoxic before the advent of deepwater convection in winter [Beutel and Horne, 1999]. As a result, anoxic products such as methane, hydrogen sulfide, ammonia, iron, manganese, and phosphorus are formed [Gächter and Müller, 2003]. These conditions cause environmental and drinking water treatment problems, which vary depending on the water use. For drinking water sources, water depleted of DO may lead to taste and odor problems, increased treatment costs, and increased formation of disinfection by-products [Cooke et al., 1993]. For cold-water fisheries, low hypolimnetic DO stresses or eradicates fish populations, and eggs deposited in anoxic sediments may not develop. Hypoxia itself has been shown to be an endocrine disruptor and negatively impacts fish reproduction [Wu et al., 2003]. Anoxic reservoir releases also negatively impact downstream water quality [Beutel and

\footnotetext{
${ }^{1}$ Department of Civil and Environmental Engineering, Virginia Polytechnic Institute and State University, Blacksburg, Virginia, USA.

${ }^{2}$ Now at Applied Aquatic Ecology, Swiss Federal Institute for Environmental Science and Technology, Kastanienbaum, Switzerland.

${ }^{3}$ Applied Aquatic Ecology, Swiss Federal Institute for Environmental Science and Technology, Kastanienbaum, Switzerland.

${ }^{4}$ Baudepartement des Kantons Aargau, Abteilung für Umwelt, Aarau, Switzerland.
}

Copyright 2004 by the American Geophysical Union. 0043-1397/04/2004WR003038
Horne, 1999]. Preventing the occurrence of anoxia in the hypolimnion may be achieved with oxygenating bubbleplumes [Wüest et al., 1992] or other oxygenation systems such as the Speece Cone [McGinnis and Little, 1998] or airlift aerator [Burris et al., 2002].

[3] The advantage of hypolimnetic oxygenation is the ability to replenish DO while preserving thermal stratification [Nakamura and Inoue, 1996; Beutel and Horne, 1999]. Bubble-plume diffusers inject air or oxygen with a relatively weak gas flow rate using small $(<2 \mathrm{~mm}$ diameter) bubbles [Wüest et al., 1992; McGinnis and Little, 2002]. This application lends itself to deeper lakes where the bulk of the bubbles dissolve in the hypolimnion, and the plume momentum is small enough to prevent intrusion into the thermocline, which would otherwise lead to warming of the hypolimnion [Wüest et al., 1992]. Penetration of phosphorus-laden plume water into the photic zone can also fuel further algal growth. Minimizing these potential problems requires better understanding of the performance of bubble plumes. In addition, the plume-lake interaction, particularly in the near field, may play a significant role in determining plume behavior.

[4] No thorough full-scale studies have been undertaken to investigate plume-lake interactions. While many bubbleplume models have been developed, most were tested in laboratory settings [McDougall, 1978; Asaeda and Imberger, 1993; Borchers et al., 1999; Brevik and Kristiansen, 2002] or in limited in situ studies [Wüest et al., 1992; Lemckert and Imberger, 1993; Mobley, 1997; Johnson et al., 2000]. Previous models typically assume steady state conditions and do not account for short- and long-term temporal and spatial alteration of the density structure or water quality with the associated change in plume dynamics. Such 


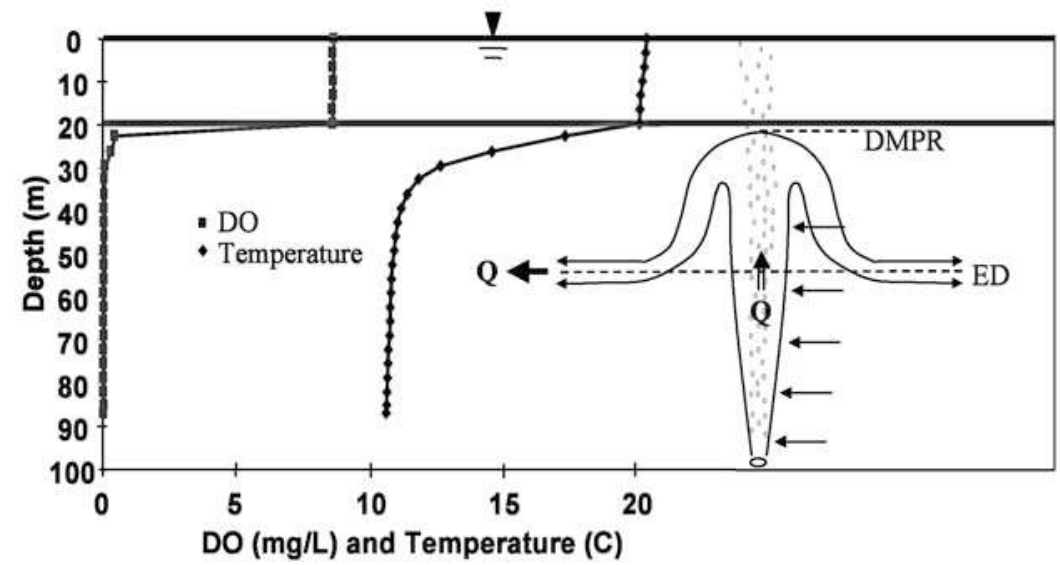

Figure 1. Schematic of a bubble-plume in a stratified lake. Typical dissolved oxygen (DO) (squares) and temperature (diamonds) profiles are shown to illustrate boundary conditions for the plume. DMPR is the depth of maximum plume rise, ED is the equilibrium depth, and Q is the volumetric plume flow rate.

changes may result from seasonal (climatic) warming and cooling, reservoir operation (withdrawal), inflow, seiching, and more importantly for this study, the plume-lake interaction itself.

[5] This paper demonstrates that a more complex plumelake interaction exists than generally assumed and that knowledge of this interaction is necessary to correctly simulate plume dynamics, oxygen transfer efficiency, and associated large-scale transport phenomena. Using a combination of field measurements and modeling we (1) study the bubble-plume and the plume-lake interaction, (2) determine from the data and model the appropriate boundary conditions, and (3) use the new understanding of the plume behavior in a full-scale validation of the Wüest et al. [1992] bubble-plume model.

\section{Bubble-Plume Model}

[6] Figure 1 shows the conventional concept of a bubbleplume in a lake. A model that predicts hydrodynamics and constituent concentrations in these circular bubble-plumes is investigated. The plume model theory is based on horizontally integrated equations of the conservation of mass, momentum, heat, salinity and gas species [McDougall, 1978]. Entrainment is assumed proportional to the local plume velocity and circumference [Morton, 1959]. The plume model also includes the effects of stratification due to vertical temperature and salinity gradients. A key contribution of the Wüest et al. [1992] model was the use of a variable buoyancy flux to account for changing bubble size not only due to decompression and thermal expansion, but also gas dissolution and stripping. While previous studies neglected gas exchange, it is particularly important in deep systems, or for weak plumes, where gas transfer can be rapid. The model also uses bubble-size-dependent equations for bubble rise velocity and mass transfer coefficients, as well as a temperature-dependent solubility constant (Table 1). The gas transfer component of the plume model has been independently validated in discrete-bubble oxygen transfer tests [McGinnis and Little, 2002], and in a full-scale airlift aerator [Burris et al., 2002].

[7] Table 2 lists the key variables of the plume model. On the basis of eight flux equations (Table 3) that are solved simultaneously, the model predicts water flow rate, water entrainment, gas transfer, plume temperature, constituent concentrations (oxygen, nitrogen and salinity), depth of maximum plume rise (DMPR), and equilibrium depth (ED) for the given boundary conditions of diffuser depth and diameter, applied gas flow rate, initial bubble size, and boundary profiles (temperature, DO, and salinity). The initial velocity is determined on the basis of a Froude number of 1.6 [Wüest et al., 1992], where

$$
\mathrm{Fr}=\frac{\mathrm{v}}{\left[2 \lambda \mathrm{bg}\left(\rho_{\mathrm{a}}-\rho_{\mathrm{p}}\right) / \rho_{\mathrm{p}}\right]^{1 / 2}} .
$$

A top hat distribution is used for water velocity, temperature, salinity, bubble velocity, and gaseous constituent concentrations. The plume radius for dissolved species and tempera-

Table 1. Parameterizations for Solubility Constant, Mass Transfer Coefficient, and Bubble Rise Velocity ${ }^{\mathrm{a}}$

\begin{tabular}{ll}
\hline \multicolumn{1}{c}{ Equation } & \multicolumn{1}{c}{ Range } \\
\hline $\mathrm{H}_{\mathrm{O}}=2.125-5.021 \times 10^{-2} \mathrm{~T}+5.77 \times 10^{-4} \mathrm{~T}^{2}\left(\mathrm{~mol} \mathrm{~m}^{-3} \mathrm{bar}^{-1}\right)$ & \\
$\mathrm{H}_{\mathrm{N}}=1.042-2.450 \times 10^{-2} \mathrm{~T}+3.171 \times 10^{-4} \mathrm{~T}^{2}\left(\mathrm{~mol} \mathrm{~m}^{-3} \mathrm{bar}^{-1}\right)$ & $\mathrm{r}<6.67 \times 10^{-4} \mathrm{~m}$ \\
$\mathrm{~K}_{\mathrm{L}}=0.6 \mathrm{r}, \mathrm{m} \mathrm{s}^{-1}$ & $\mathrm{r} \geq 6.67 \times 10^{-4} \mathrm{~m}$ \\
$\mathrm{~K}_{\mathrm{L}}=4 \times 10^{-4}, \mathrm{~m} \mathrm{~s}^{-1}$ & $\mathrm{r}<7 \times 10^{-4} \mathrm{~m}$ \\
$\mathrm{v}_{\mathrm{b}}=4474 \mathrm{r}^{1.357}, \mathrm{~m} \mathrm{~s}^{-1}$ & $7 \times 10^{-4} \leq \mathrm{r}<5.1 \times 10^{-3} \mathrm{~m}$ \\
$\mathrm{v}_{\mathrm{b}}=0.23, \mathrm{~m} \mathrm{~s}^{-1}$ & $\mathrm{r} \geq 5.1 \times 10^{-3} \mathrm{~m}$ \\
$\mathrm{v}_{\mathrm{b}}=4.202 \mathrm{r}^{0.547}, \mathrm{~m} \mathrm{~s}^{-1}$ & \\
\hline
\end{tabular}

${ }^{\mathrm{a}}$ See Wüest et al. [1992]. 
Table 2. Eight Dynamic Variables That Form the Basis of the Bubble-Plume Model

\begin{tabular}{lll}
\hline \multicolumn{1}{c}{ Variable } & \multicolumn{1}{c}{ Definition } & \multicolumn{1}{c}{ Units } \\
\hline Water volume flux & $\mathrm{Q}=\pi \mathrm{b}^{2} \mathrm{v}$ & $\mathrm{m}^{3} \mathrm{~s}^{-1}$ \\
Momentum flux & $\mathrm{M}=\pi \mathrm{b}^{2} \mathrm{v}^{2}$ & $\mathrm{~m}^{4} \mathrm{~s}^{-2}$ \\
Temperature flux & $\mathrm{F}_{\mathrm{T}}=\mathrm{QT}_{\mathrm{p}}$ & ${ }^{\circ} \mathrm{C} \mathrm{m}^{-3} \mathrm{~s}^{-1}$ \\
Dissolved solids flux & $\mathrm{F}_{\mathrm{s}}=\mathrm{QS} \rho_{\mathrm{w}}$ & $\mathrm{g} \mathrm{s}^{-1}$ \\
Dissolved gas fluxes (DO and DN) & $\mathrm{F}_{\mathrm{D}_{\mathrm{i}}}=\mathrm{QC}_{\mathrm{i}}$ & $\mathrm{mol} \mathrm{s}^{-1}$ \\
Gas fluxes $\left(\mathrm{O}_{2}\right.$ and $\left.\mathrm{N}_{2}\right)$ & $\mathrm{F}_{\mathrm{G}_{\mathrm{i}}}=\pi \mathrm{b}^{2} \lambda^{2}\left(\mathrm{v}+\mathrm{v}_{\mathrm{b}}\right) \mathrm{y}_{\mathrm{i}}$ & $\mathrm{mol} \mathrm{s}^{-1}$ \\
\hline
\end{tabular}

ture is assumed to be equal to the radius b of the top hat plume velocity profile, while the bubbles occupy an inner core of radius, $\lambda b(\lambda<1)$. The bubble diffuser source is assumed to produce bubbles at a constant rate and uniform size that are evenly distributed over the entire diffuser, $\lambda b_{o}$. Bubble coalescence is neglected. The properties of water entrained into the plume are assumed equal to the ambient water at that depth.

\section{Research Approach}

[8] To fully validate the plume model, it is necessary to experimentally resolve the appropriate boundary conditions, determine the DMPR and in-plume constituent distributions, verify the entrainment coefficient, and better quantify the plume fallback behavior and plume-lake interaction. Entrainment resulting in plume spreading is typically treated as a constant, an assumption that is somewhat counterintuitive given the variable nature of the plume boundary conditions. These include changes in plume velocity resulting in different levels of turbulence at the plume/ambient water interface, the variation in density gradient, and mixing that may occur in the region where the plume stops rising. Furthermore, the spreading (or lack of spreading) of the bubble core resulting from entrainment affects the DMPR and the constituent concentration distributions in the plume (i.e., Gaussian versus top hat). The near-field detrainment and behavior of the plume return flow, or fallback water, is not fully understood and is an area that is typically weakly addressed, but which may have significant impact on the plume itself [Asaeda and Imberger, 1993; Lemckert and Imberger, 1993; Brevik and Kristiansen, 2002]. The far-field response to the plume entrainment (inflow) and detrainment (return flow) is also unclear, and will affect the ultimate location of oxygenated water in the lake and long-term changes in plume characteristics.

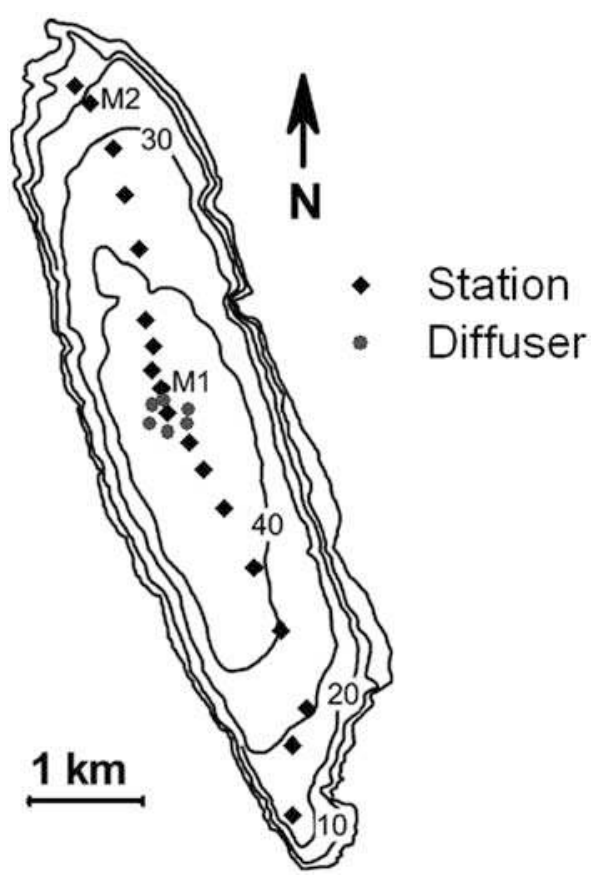

Figure 2. Lake Hallwil bathymetry showing conductivity, temperature, and depth (CTD) sampling stations (diamonds), diffuser locations (circles), mooring 1 (M1), and mooring 2 (M2).

[9] The in situ study was undertaken in Lake Hallwil, a medium-sized lake located on the Swiss Plateau (Figure 2 and Table 4) [Stöckli and Schmid, 1987; Scheidegger et al., 1994]. Lake Hallwil is a phosphorous-limited, eutrophic lake that has experienced anoxia during the summer for the past century. In 1986, the "Tanytarsus" diffuser system (Figure 3) was installed to combat anoxia and as an ultimate restoration technique [Stöckli and Schmid, 1987; Wehrli and Wüest, 1996]. The system can be switched between artificial mixing mode using coarse air bubbles, and hypolimnetic oxygenation or aeration mode using fine oxygen or air bubbles, respectively. The six $6.5-\mathrm{m}$ diameter diffusers in Lake Hallwil are in a 300-m diameter circular configuration near the center of the lake (Figure 2 and Table 4). Each diffuser is operated using air or oxygen during the summer, and air for artificial mixing in the winter. Table 5 shows the air and oxygen flow rates employed in 2001 and 2002.

[10] To establish appropriate boundary conditions for the plume model, high spatial resolution of the near-plume environment is required. The lake monitoring and testing

Table 3. Eight Nonlinear Differential Flux Equations of the Bubble-Plume Model

\begin{tabular}{ll}
\hline Water volume flux & Equations \\
Momentum flux & $\frac{\mathrm{dQ}}{\mathrm{dz}}=2 \alpha \pi \mathrm{bv}$ \\
Temperature flux & $\frac{\mathrm{dM}}{\mathrm{dz}}=\frac{\rho_{\mathrm{a}}-\rho_{\mathrm{p}}}{\rho_{\mathrm{p}}} \mathrm{gb}^{2} \lambda^{2}+\frac{\rho_{\mathrm{a}}-\rho_{\mathrm{w}} \mathrm{g} \pi \mathrm{b}^{2}\left(1-\lambda^{2}\right)}{\rho_{\mathrm{p}}}$ \\
Dissolved solids flux & $\frac{\mathrm{dF} \mathrm{T}}{\mathrm{dz}}=2 \alpha \pi \mathrm{bvT}$ \\
Dissolved gas fluxes (DO and $\mathrm{DN})$ & $\frac{\mathrm{dF}}{\mathrm{dz}}=2 \alpha \pi b v \rho_{\mathrm{a}} \mathrm{S}_{\mathrm{a}}$ \\
Gas fluxes $\left(\mathrm{O}_{2}\right.$ and $\left.\mathrm{N}_{2}\right)$ & $\frac{\mathrm{dF} \mathrm{D}_{\mathrm{i}}}{\mathrm{dz}}=2 \alpha \pi b v C_{\mathrm{ia}}+\frac{4 \pi \mathrm{r}^{2} \mathrm{~N}_{\mathrm{v}}+\mathrm{V}_{\mathrm{b}}\left(\mathrm{H}_{\mathrm{i}} \mathrm{P}_{\mathrm{i}}-\mathrm{C}_{\mathrm{i}}\right)}{4 \pi \mathrm{r}^{2} \mathrm{~N}_{\mathrm{V}_{\mathrm{L}}}\left(\mathrm{H}_{\mathrm{i}} \mathrm{P}_{\mathrm{i}}-\mathrm{C}_{\mathrm{i}}\right)}$ \\
\hline
\end{tabular}


Table 4. Characteristic Features of Lake Hallwil and the Diffuser System

\begin{tabular}{ll}
\hline \multicolumn{1}{c}{ Parameter } & \multicolumn{1}{c}{ Value } \\
\hline Maximum depth, $\mathrm{m}$ & 46.5 \\
Mean depth, m & 28.9 \\
Surface area, $10^{6} \mathrm{~m}^{2}$ & 9.9 \\
Total water volume, $10^{6} \mathrm{~m}^{3}$ & 285 \\
Diffuser geometry & circular \\
Number of diffusers & 6 \\
Diffuser diameter, m & 6.5 \\
Average diffuser depth, m & 46 \\
Gas flow rate to all diffusers, $\mathrm{Nm}^{3} \mathrm{~h}^{-1 \mathrm{a}}$ & $46-148\left(\mathrm{O}_{2}\right)$ \\
& $180($ air) \\
\hline
\end{tabular}

${ }^{\mathrm{a}}$ Denotes gas at 1 bar and $0^{\circ} \mathrm{C}$.

program began in April 2001. Measurements focused on the entire lake response to hypolimnetic oxygenation in 2001 and the near-field plume environment in 2002. During 2001, transects were measured weekly to monthly at 18 locations along the main axis of Lake Hallwil (Figure 2) using a SeaBird SBE19 CTD profiler. The SBE19 samples at $2 \mathrm{~Hz}$ and measures, besides conductivity, temperature and depth (CTD), also DO, light transmission (at $660 \mathrm{~nm}$ ) and $\mathrm{pH}$. In 2002, spatially high resolution (1-2 m) transects were obtained across an individual plume. Ropes were fixed on the water surface using existing heavy-duty buoys as well as anchors. A floating rope was placed directly over a single plume and the position of the rope was verified using GPS with no observed movement. A total of 32 profiles were measured, with the $0-\mathrm{m}$ point located above what visually appeared to be the center of the plume. Profiles were measured every meter between 0 and $10 \mathrm{~m}$ and every $2 \mathrm{~m}$ between 10 and $20 \mathrm{~m}$, with the transect extending in both directions from the center of the plume.

[11] During the monitoring program, two thermistor moorings were deployed $100 \mathrm{~m}$ from the diffuser ring (M1) and on the north end of Lake Hallwil (M2) (Figure 2). Although the thermistor configuration and type varied during the study, deployment was nearly continuous. The thermistors were high-resolution Richard Branker TR1000 and TR-1050 as well as 8- and 12-bit Vemco Minilog sensors. Additionally, an RD Instruments Workhorse ADCP (acoustic Doppler current profiler, referred to as "RDI")

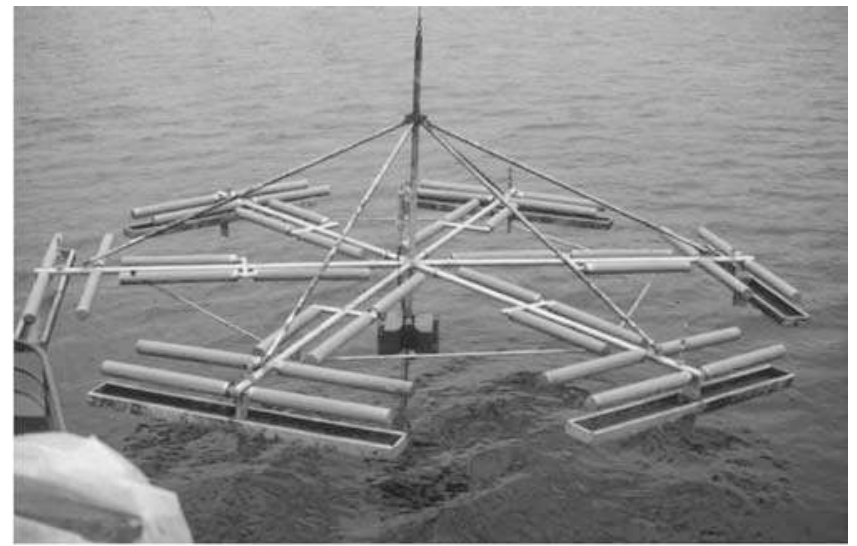

Figure 3. One of the six $6.5-\mathrm{m}$ diameter Tanytarsus diffusers.
Table 5. Diffuser Air and Oxygen Flow Rates During the 20012002 Monitoring Program ${ }^{\mathrm{a}}$

\begin{tabular}{llcc}
\hline \multicolumn{1}{c}{ Start Date } & \multicolumn{1}{c}{ Mode } & $\mathrm{Q}_{\mathrm{g}}, \mathrm{Nm}^{3} \mathrm{~h}^{-1}$ & $\mathrm{O}_{2}$ Input, $\mathrm{t} \mathrm{d}^{-1}$ \\
\hline 2 April 2001 & aeration & 180 & 1.2 \\
7 May 2001 & oxygenation & 46 & 1.6 \\
25 June 2001 & aeration & 180 & 1.2 \\
2 July 2001 & oxygenation & 46 & 1.6 \\
13 July 2001 & oxygenation & 105 & 3.6 \\
22 August 2001 & oxygenation & 148 & 5.0 \\
15 October 2001 & oxygenation & 113 & 3.6 \\
23 October 2001 & aeration & 180 & 1.2 \\
30 October 2001 & circulation (air) & 510 & 3.5 \\
20 January 2002 & circulation (air) & 240 & 1.6 \\
18 March 2002 & aeration & 180 & 1.2 \\
22 July 2002 & oxygenation & 89 & 3.0 \\
30 September 2002 & aeration & 180 & 1.2 \\
\hline
\end{tabular}

${ }^{\mathrm{a}}$ The total flow is evenly distributed among all six diffusers, and coarse air bubbles are used during winter circulation.

$(600 \mathrm{kHz})$ was deployed on the bottom of the lake facing upward. The current profiler was positioned near the diffuser ring at M1 (Figure 2) throughout most of the study and measured the three-dimensional velocity vectors. For a typical deployment, the RDI was configured to measure velocity profiles throughout the entire water column within $50-\mathrm{cm}$ vertical bins. Profiles were recorded every $5 \mathrm{~min}$ as averages over 150 individual pings.

\section{Observations and Model Comparisons}

\subsection{Plume-Induced Near-Field Environment}

[12] The plume and its near field were probed at a high spatial resolution. Figures 4-6 show high-resolution contour plots for temperature, DO and light transmission on 18 July 2002, when the diffuser was operating with air at $180 \mathrm{Nm}^{3} \mathrm{~h}^{-1}$, corresponding to $1.3 \mathrm{t}-\mathrm{O}_{2} \mathrm{~d}^{-1}$ (Table 5). From the contour plots, the plume appears highly turbulent and fairly heterogeneous in nature. The high-resolution temperature contour plot (Figure 4) indicates an approximately Gaussian distribution as expected. The DMPR is $7.5 \mathrm{~m}$ with

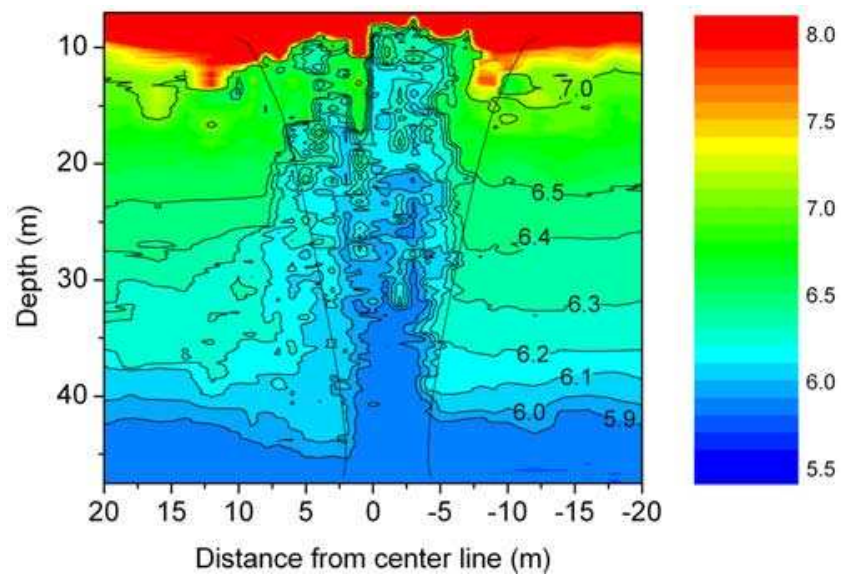

Figure 4. The 18 July 2002 temperature $\left({ }^{\circ} \mathrm{C}\right)$ with predicted plume diameter overlaid. For clarity the contours were scaled to show only values in the range of $5.5^{\circ} \mathrm{C}-8^{\circ} \mathrm{C}$, with temperatures above 8.0 shaded red and temperatures below 5.5 shaded blue. 


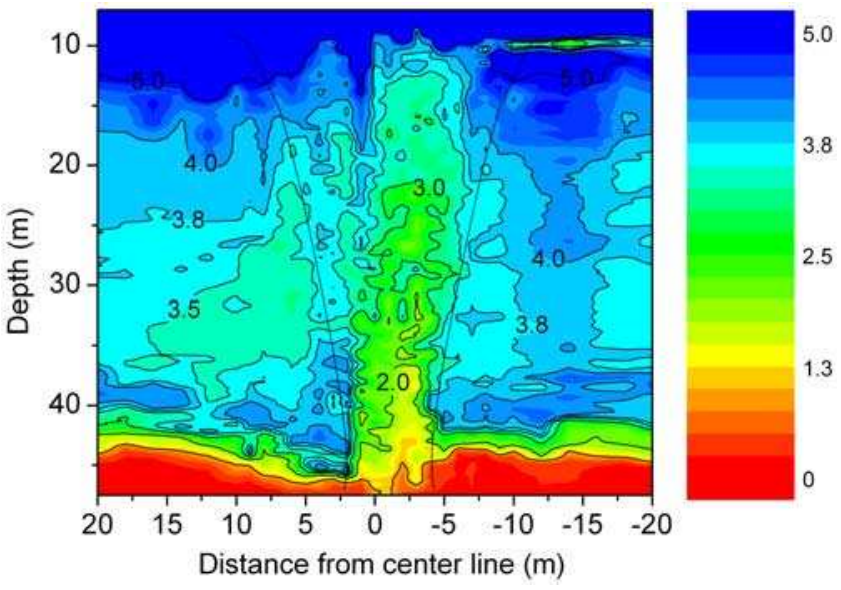

Figure 5. The 18 July 2002 dissolved oxygen (DO) $\left(\mathrm{g} \mathrm{m}^{-3}\right)$ with predicted plume diameter overlaid. For clarity the DO contours were scaled to show only the values in the range of $0-5 \mathrm{~g} \mathrm{~m}^{-3}$, with DO above 5 shaded blue.

the average of $9.4 \mathrm{~m}$ taken at the $7^{\circ} \mathrm{C}$ contour line. Multiple detrainments occur in the northerly (left) direction, as indicated by the temperature, DO, and light transmission data (Figures 4-6). Such detrainment is probably the result of horizontal advective cross flow due to internal seiching (discussed in section 4.2). The depression in the temperature isopleths and the higher DO that plunges almost to the lake bottom immediately to the north (left in Figures 4-6) of the plume is a result of either detrained water that passes the ED due to momentum or local drawdown resulting from plume upflow.

[13] Within the plume, the DO concentration is substantially lower than in the ambient lake water (Figure 5). The reason is that the plume initially entrains water from the anoxic bottom boundary layer and the DO increase in the rising plume due to gas transfer from the air bubbles (instead of oxygen) is modest. Under these conditions, the DO concentration within the plume is governed by the initial conditions at the diffuser and entrainment of sur-

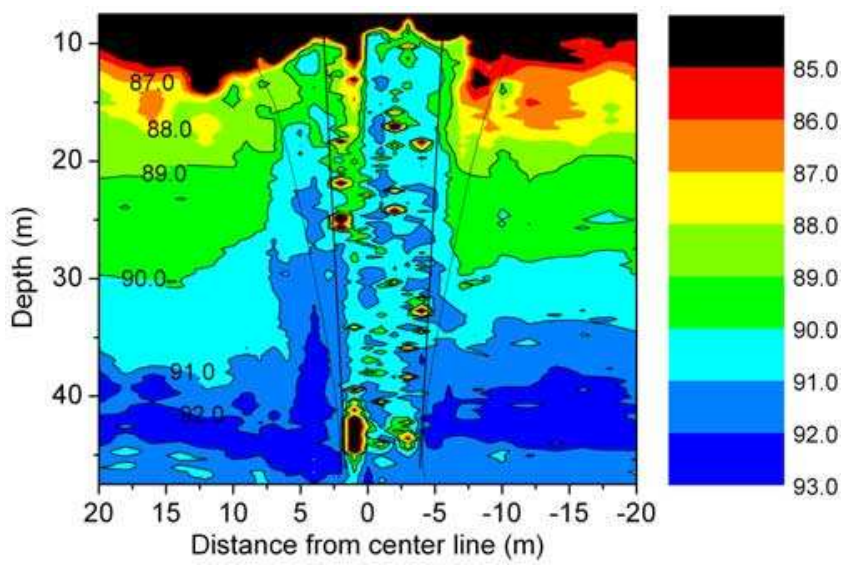

Figure 6. The 18 July 2002 light transmission (\%) at $660 \mathrm{~nm}$ with predicted plume diameter overlaid. Interior lines indicate observed extent of bubble core. For clarity the light transmission contours were scaled to show only measurements in the range of $85-93 \%$, with values above $93 \%$ shaded blue and values below $85 \%$ shaded black. rounding water. The low-transmissivity spikes within the plume shown in Figure 6 are also of interest. These spikes are a result of bubbles passing the light transmission meter, suggesting the location of the bubble core. The lines superimposed on Figure 6 indicate the extent of the bubble core, which appears to spread only slightly. The bubbles are rising approximately $25 \mathrm{~cm} \mathrm{~s}^{-1}$ faster than the plume water [McGinnis and Little, 2002], making them less subject to spreading due to entrainment as there is considerably less bubble contact time. While not conclusive, this almost nonexpanding bubble core agrees with the laboratory observations of McDougall [1978], while the bubble-plume model assumes the bubble core expands in width at the same rate as the outer core. The more concentrated bubble core will result in a higher local DMPR than the top hat assumption, or even a Gaussian profile, would yield. This issue will be addressed subsequently.

\subsection{Far-Field Hypolimnetic Structure}

[14] The whole-lake contour plots from 24 July, 16 August, and 27 September 2001 show typical temperature and oxygen distributions (Figures 7 and 8, respectively) in Lake Hallwil during the 2001 stratification season when

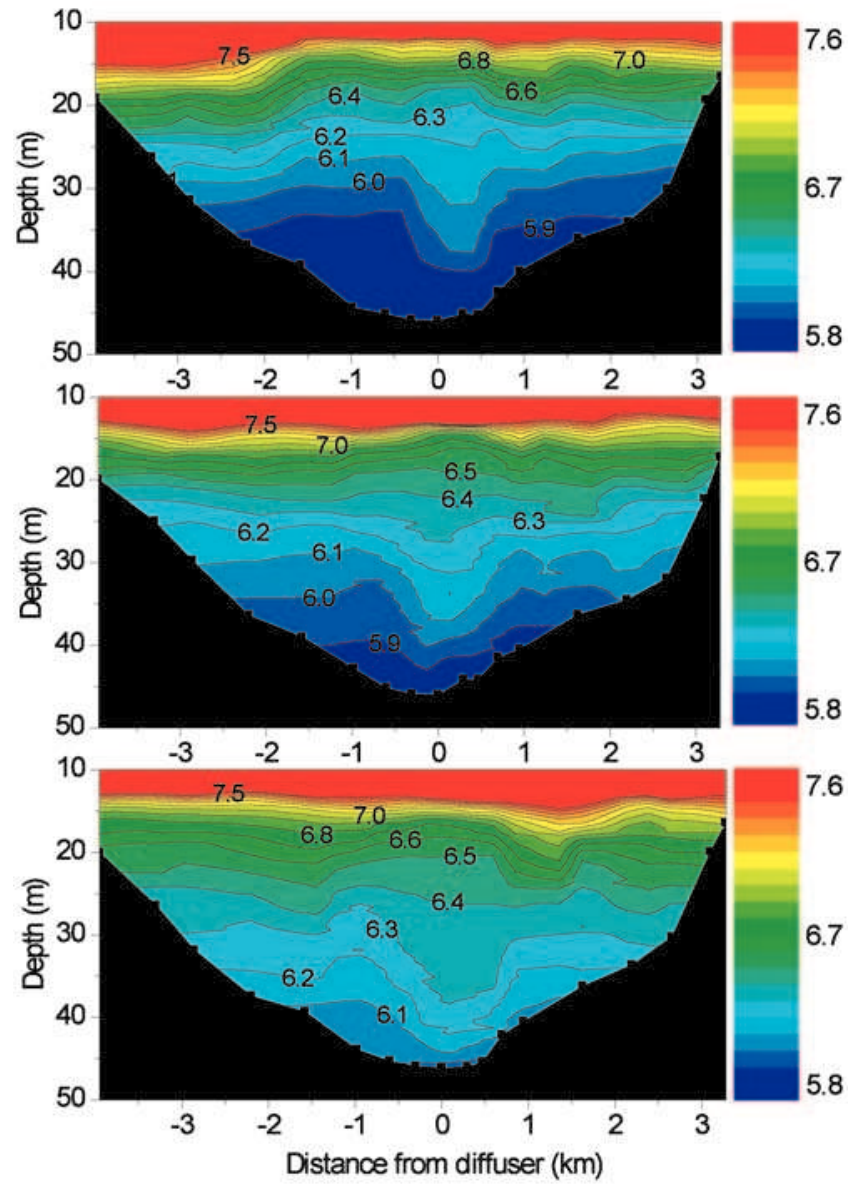

Figure 7. The (top) 24 July, (middle) 16 August, and (bottom) 27 September 2001 temperature contours $\left({ }^{\circ} \mathrm{C}\right)$. The $x$ axis zero point is located at the center of the $300-\mathrm{m}$ diameter diffuser ring. The contours were interpolated from 18 CTD profiles (locations indicated by black squares at the bottom of the plots) sampled along the centerline of the lake (see Figure 2 map showing 18 sampling stations). 

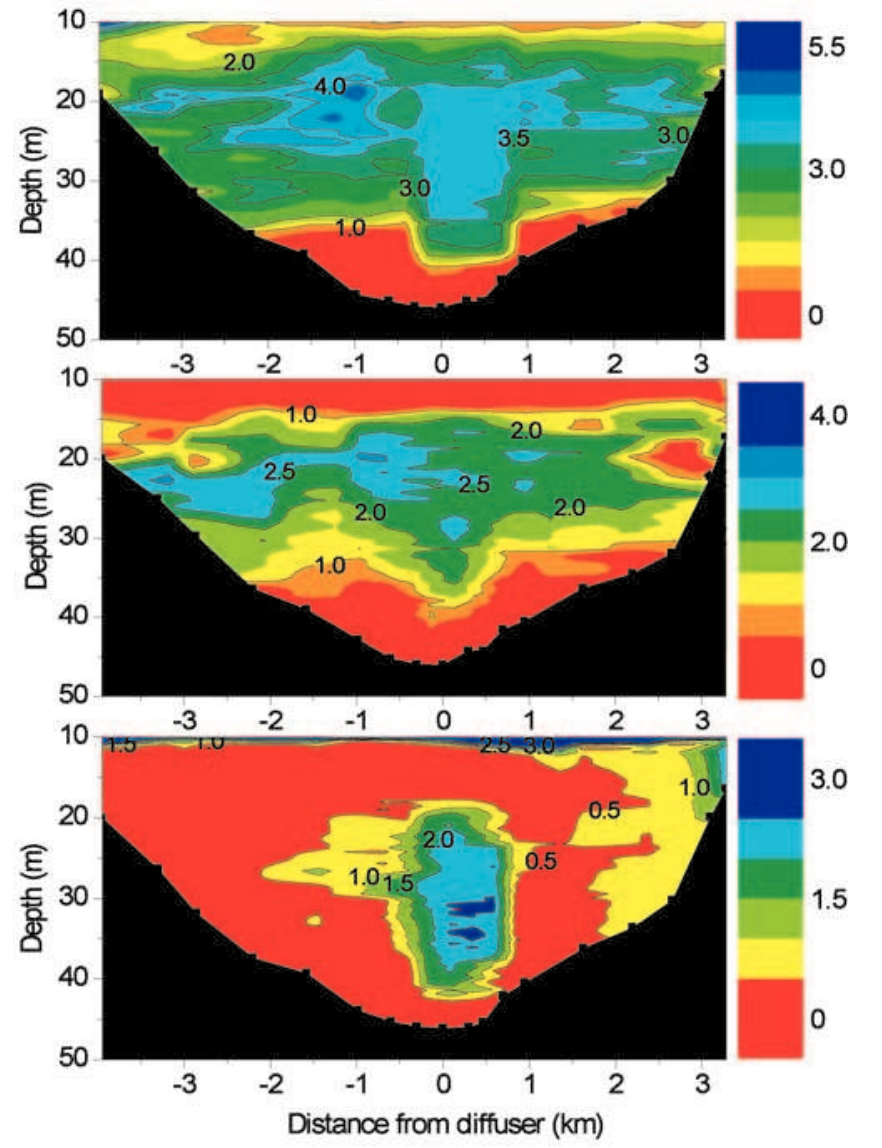

Figure 8. The (top) 24 July, (middle) 16 August, and (bottom) 27 September 2001 DO contours $\left(\mathrm{g} \mathrm{m}^{-3}\right)$. Note different scales. The $x$ axis zero point is located at the center of the 300-m-diameter diffuser ring. The contours were interpolated from $18 \mathrm{CTD}$ profiles (locations indicated by black squares at the bottom of the plots) sampled along the centerline of the lake (see Figure 2 map showing 18 sampling stations).

the plume was operated using pure oxygen at the flow rates listed in Table 5. The typical, two-dimensional nature of the mushroom-shaped plume is clearly depicted in the oxygen contours. The nearly $1-\mathrm{km}$-wide depression of the isotherms in the deep central region between 25 and $40 \mathrm{~m}$ indicates the presence of warmer water, while the slightly convex isotherms in the shallower region indicate cooler water, demonstrating the impact of the six circular plumes on the hypolimnion. The $1-\mathrm{km}$-wide near-field plume-induced structure is a result of seiching, as explained below.

[15] The persistent warmer water at lower depths in the seiche-enhanced near field may be explained by plume water fallback from either detrainment at the top of the plume, detrainment along the rising plume (multiple detrainment), or a combination of both. It was surprising to observe plume fallback water at depths lower then the estimated ED or point of neutral buoyancy. This could also occur because of multiple detrainments, with some denser plume water detraining lower down in the plume. It is further hypothesized that after the higher than ambient density plume water detrains at the DMPR, momentum carries the fallback water past the point of neutral buoyancy and toward the lake bottom before finally rising again to the
$\mathrm{ED}$, which is estimated to be between 20 and $30 \mathrm{~m}$ based on the temperature and DO structures shown in Figures 7 and 8 , respectively. This oscillation can be described by the local buoyancy frequency, N. This phenomenon was also observed, although to a lesser extent, by Lemckert and Imberger [1993].

[16] A direct observation of the maximum fallback depth was acquired from the ADCP velocity measurements in June 2002 (Figure 9). For this purpose, the ADCP was bottom deployed (facing upward) on the north side of the diffuser ring approximately $30 \mathrm{~m}$ from the most northerly diffuser (Figure 2). The contour plot in Figure 9 shows the measured downward velocity (upward velocity is positive). There were no significant upward velocities measured during this period, and for clarity the low values were omitted from the plot. Downward velocities reached $18 \mathrm{~mm} \mathrm{~s}^{-1}$, much higher than typical vertical velocities in a lake interior [Wüest and Lorke, 2003], and were observed as deep as $40 \mathrm{~m}$. This observation is significant because, as the plume rises, it entrains a large fraction of the fallback water, which has different properties than in the far field, and results in short-circuiting of the detraining plume water.

[17] Although the applied gas flow rate was constant, the observed downward velocities show a regular periodicity (Figure 9), which we interpret as the result of plume wandering due to basin-scale internal (baroclinic) seiching of the lake water body (Figure 10). As previously mentioned, this internal seiching motion explains the horizontal dispersion of the plume "signature." As indicated on the temperature and DO contour plots (Figures 7 and 8), the horizontal extent of the seiche-induced zone (higher temperature and DO) at the lower depths is approximately $1 \mathrm{~km}$ wide and slightly shifted to the north (right on Figures 7 and 8). This is substantially larger than would be expected for the six individual plumes arranged in a 300 -m-diameter ring in quiescent water. Owing to the geometry of the basin and a 24-hour wind forcing, rather intense and persistent first-mode seiching occurs, typically with a period of approximately 12 hours (Figure 10) [Gwaze, 2003]. The hypolimnetic seiche currents are sinusoidal with an amplitude of $\sim 3.5 \mathrm{~cm} \mathrm{~s}^{-1}$ and an average current velocity of $1 \mathrm{~cm} \mathrm{~s}^{-1}$ during June and July 2001 (Figure 10). The distance this water moves at $1(3.5) \mathrm{cm} \mathrm{s}^{-1}$

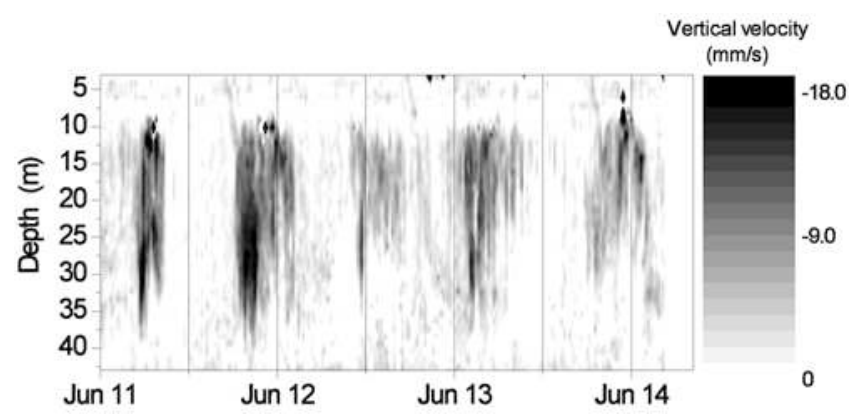

Figure 9. Acoustic Doppler current profiler (ADCP) measurements in June 2002 showing downward flowing water near the northern diffuser (M1 in Figure 2). Velocity is defined as positive upward. For clarity, positive values are omitted from the plot. The 12-hour periodicity in downwelling flow is caused by plume wandering due to horizontal seiche currents. 


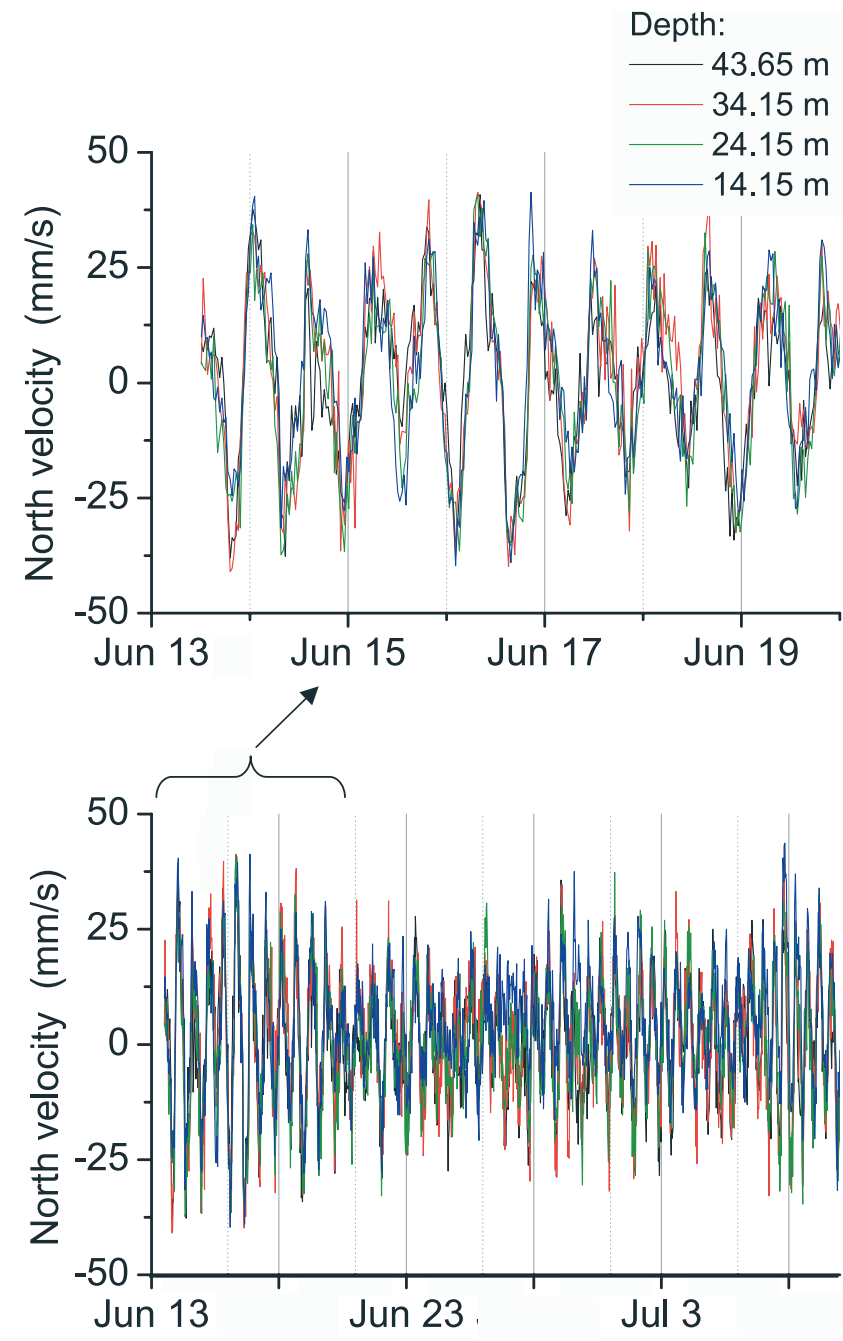

Figure 10. ADCP measurements in June-July 2001 showing horizontal (northerly) hypolimnetic current velocities. Velocities are nearly constant with depth in the hypolimnion with a period of approximately 12 hours.

over a 6-hour period is $220(750) \mathrm{m}$, and thus seiching can significantly increase the horizontal dispersion of the localized plume signature. These observations further support the hypothesis that the plume generates a near-field environment, which strongly affects the plume hydrodynamics and constituent concentrations.

\subsection{Compensation Flow in the Far Field}

[18] Depending on operating conditions, a large portion of plume fallback water may be re-entrained by the plume, leading to short-circuiting. The traditional and new conceptualized plume flow patterns are shown in Figure 11. The far-field vertical compensation flow was calculated by balancing temperature in layers at different depths. The respective temporal and vertical gradients were determined using the high-resolution thermistor data collected at the mooring installed $100 \mathrm{~m}$ north of the diffuser ring (M1 on Figure 2). The horizontally averaged vertical far-field transport is given by

$$
\mathrm{Q}(\mathrm{z})=\mathrm{A}_{\mathrm{z}}(\mathrm{z}) \frac{\partial \mathrm{T} / \partial \mathrm{t}(\mathrm{z})}{\partial \mathrm{T} / \partial \mathrm{z}(\mathrm{z})}
$$

(positive Q implies upward advective transport). To ensure the validity of this calculation, it was first necessary to determine the relative magnitude of the plume-induced mixing (apparent vertical turbulent diffusivity) with respect to the natural turbulent diffusivity. The apparent hypolimnetic turbulent diffusivity was calculated [Powell and Jassby, 1974] by

$$
\mathrm{k}_{\mathrm{t}}=\frac{\int_{\mathrm{z} \max }^{\mathrm{z}} \mathrm{A}\left(\mathrm{z}^{\prime}\right)\left(\partial \mathrm{T}\left(\mathrm{z}^{\prime}, \mathrm{t}\right) / \partial \mathrm{t}\right) \mathrm{dz^{ \prime }}}{\mathrm{A}(\mathrm{z}) \cdot(\partial \mathrm{T} / \partial \mathrm{z})}
$$

for both the 13-30 July 2001 and May-June 2002 data and found to be in the range of $0.16-17 \mathrm{~cm}^{2} \mathrm{~s}^{-1}$. This range is much higher than the vertical diffusivity of approximately $0.03 \mathrm{~cm}^{2} \mathrm{~s}^{-1}$ reported for Lake Alpnach, a Swiss lake with similar size and stronger wind exposure but with no hypolimnetic oxygenation system [Wüest et al., 2000]. Therefore the vertical transport induced by the plume is much greater than naturally occurring vertical turbulent diffusivity, so the latter can be considered negligible in the plume-affected hypolimnion. The predicted far-field plume entrainment flow rate at each depth was then estimated by calculating the expected vertical divergence $\partial \mathrm{Q} / \partial \mathrm{z}$ of the far-field transport from the plume model. This was directly compared to the observed far-field advective transport, as any water entrained by the upward plume at a particular depth below the ED should result in an equal amount

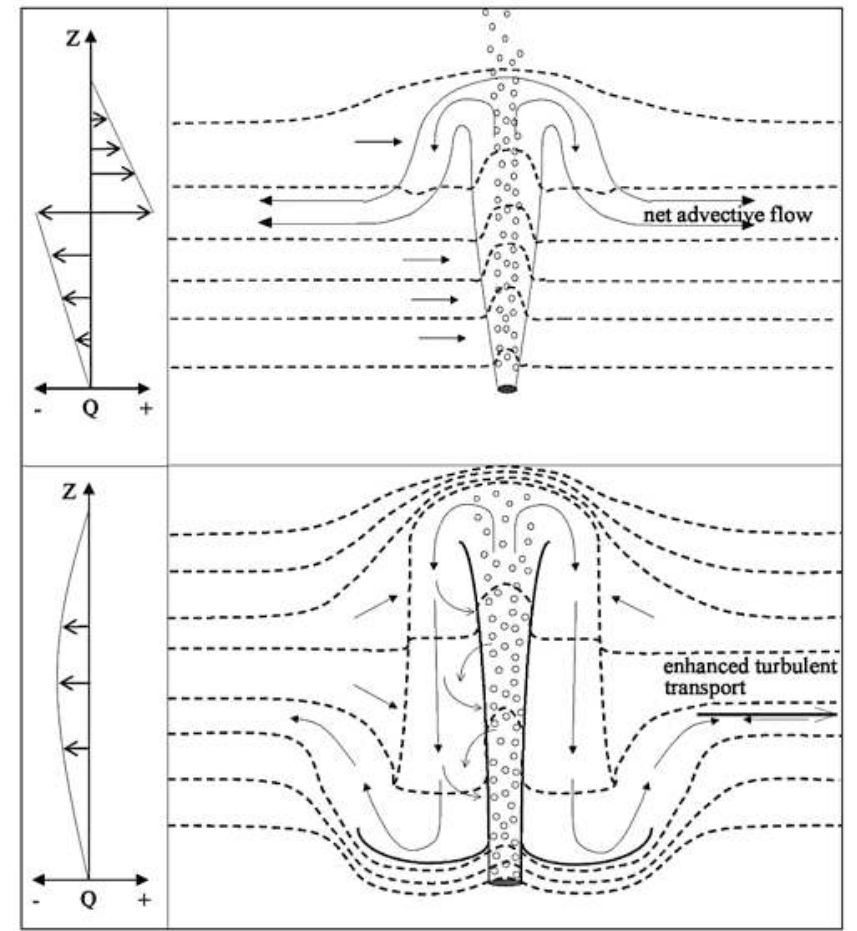

Figure 11. (top) Traditional plume model approach and (bottom) new model concept of plume behavior and shortcircuiting in deep lakes (not to scale). Dashed line indicates constant temperature isopleths demonstrating near-field alteration. Left axis shows approximate far-field vertical compensation flow rate distribution (see Figure 12). 


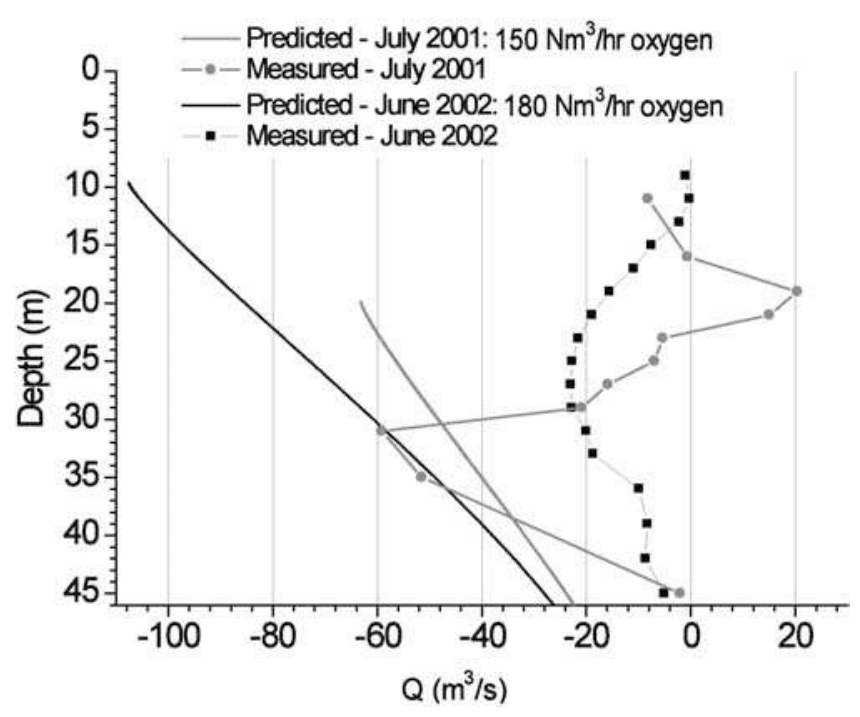

Figure 12. Predicted plume entrainment flow rate and observed far-field plume-induced advective flow rate Q (see Figure 11). Negative values indicate downward flow. The stop points for the predicted entrainment flow rate at approximately $20 \mathrm{~m}$ for 2001 and $10 \mathrm{~m}$ for 2002 indicate the model predicted depth of maximum plume rise (DMPR).

flowing downward in the far field to replace it. These estimates neglect possible mixing at the DMPR and entrainment during plume fallback.

[19] Figure 12 shows the observed far-field advective transport with depth compared to the predicted plume transport for the 13-30 July 2001 thermistor data. The plume was operated using oxygen at $80 \%$ of the June 2002 airflow rate (Table 5). The model underpredicts the DMPR due to the improper selection of boundary profiles; however, the predicted water flow rate below the ED is close to the calculated range. For July 2001, while the shape of the observed and predicted curves do not match closely (discussed below), the averaged integrated total flow below the minimum flow at $31 \mathrm{~m}$ for both the measured and predicted curves is within $10 \%$. The zero far-field flow at $23 \mathrm{~m}$ is thought to be the upper extent of the ED with the bottom extent at around $31 \mathrm{~m}$, immediately above the minimum calculated $\mathrm{Q}$ of $-60 \mathrm{~m}^{3} \mathrm{~s}^{-1}$. The zero far-field flow at $16 \mathrm{~m}$ is thought to be the average DMPR over the 18-day period, as entrainment, and hence a far-field response does not occur above this point. This DMPR, however, is well below the lower extent $(\sim 10 \mathrm{~m})$ of the thermocline, which prevents the entrainment of warmer, metalimnetic water. The depth from 16 to $23 \mathrm{~m}$ shows a cooling, or upward flow, of water (Figure 11), similar to observations during laboratory tests performed by McDougall [1978] for weak plumes. This upward flow is a result of plume entrainment removing water above the ED (with additional water entrained during fallback) and placing it in the region of the ED. This suggests a weaker, well-defined plume and perhaps only a single detrainment at the top, limiting any short-circuiting to the zone above the lower extent of the ED.

[20] The same analysis was performed on the May-June 2002 data when a stronger plume was operated with air at $180 \mathrm{Nm}^{3} \mathrm{~h}^{-1}$ (Figure 12). The observed far-field advective flow is significantly lower than that estimated from the plume model, with a nearly Gaussian distribution in the observed flow rate versus depth. Furthermore, the area of upward advective flow is absent. Two important conclusions can be drawn from these results. The first is that the observed plume-induced advective far-field flow is much less than expected on the basis of model predictions, which is likely a result of re-entrainment of the fallback and ultimate return water. Second, the considerable underprediction in the observed far-field flow rate points to shortcircuiting at all locations along the plume. These results suggest either that fallback water is almost reaching the lake bottom, or that multiple detrainment is occurring (similar to the observations of McDougall [1978] in lab experiments for strong plumes), or both.

[21] Finally, there is an alteration in the isotherms near the plume due to enhanced mixing, with the near-field water being more vertically homogenous than the far-field temperature structure (Figure 11). That is, the temperature isopleths are much farther apart near the diffusers and vertically shifted relative to the far field. Assuming that the bulk advective transport from the far field occurs along the isopycnals, this results in a somewhat Gaussian distribution of advective vertical transport rather than the linearly increasing flow rate that would be expected if the isotherms were truly horizontal and unaltered by the plume (see Figure 11). The more vigorous mixing resulting in the more homogeneous nearfield density structure may also allow the fallback water to reach greater depths as it encounters weakly stratified water. Furthermore, because plume detrainment is likely occurring at multiple points and water is moving toward the plume at these same locations, return flow from the plumes to the far field is limited to enhanced turbulent diffusion rather than advection. Additionally, there is no upward far-field compensation flow, shown by the lack of a positive Q in Figure 12, indicating an overall warming of the hypolimnion. This warming throughout the hypolimnion is due to plume penetration into and subsequent erosion of the themocline resulting in a net downward heat flux from the thermocline and implies a slow destratification of Lake Hallwil.

\section{Model Comparison With Improved Boundary Conditions}

[22] Using the near-field boundary conditions in the plume model yielded substantial improvements in model predictions. The results of the simulation are superimposed on the contour plots (Figures 4-6) showing predicted diameter as a function of depth and the predicted DMPR. The new boundary conditions were constructed by averaging the boundary profiles measured $5 \mathrm{~m}$ on either side of the

Table 6. Model Baseline Conditions for a Single Diffuser

\begin{tabular}{lll}
\hline \multicolumn{1}{c}{ Parameter } & Variable & Value \\
\hline Diffuser depth, $\mathrm{m}$ & $\mathrm{z}^{0}$ & 46 \\
Initial plume area, $\mathrm{m}^{2}$ & $\pi\left(\mathrm{b}^{0}\right)^{2}$ & 33.2 \\
Entrainment factor & $\alpha$ & 0.11 \\
Plume diameter ratio (bubble core) & $\lambda$ & 0.8 \\
Initial Froude number & $\mathrm{Fr}^{0}$ & 1.6 \\
Air flow rate, $\mathrm{Nm}^{3} \mathrm{~h}^{-1}$ & $\mathrm{Q}_{\mathrm{g}}^{0}$ & 30 \\
Initial bubble diameter, $\mathrm{mm}$ & $\mathrm{r}^{0}$ & 2 \\
\hline
\end{tabular}




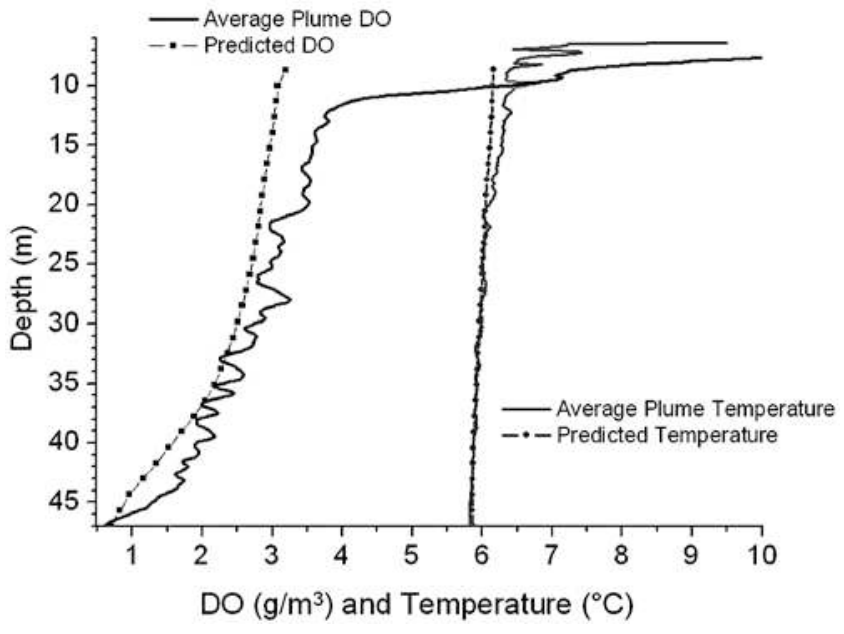

Figure 13. Averaged measured in-plume temperature and DO profile and plume-model predictions.

center of the plume and the simulation was performed using the baseline values listed in Table 6. Using the indicated profiles, the plume model predicts both the DMPR and rate of spread extremely well, given the top hat assumption versus the actual approximately Gaussian distribution. Figure 13 shows the averaged measured in-plume temperature and DO profile and the plume-model predictions. The predicted temperature profile compares well but appears to diverge at $20 \mathrm{~m}$ depth to approximately $0.3^{\circ} \mathrm{C}$ less than the measured temperature. This may be a result of the boundary profiles still being somewhat inaccurate. Depending on the direction and strength of the horizontal hypolimnetic current velocities and the plume interaction at stronger temperature gradients, the plume may entrain and detrain water at different rates and with different properties around the plume. Furthermore, the average plume temperature and DO are based only on the two-dimensional transect and may also be laterally heterogeneous. In fact, the diffuser geometry imparts an initial bubble distribution that is clearly not perfectly uniform (Figure 3). Also, as previously discussed, the plume boundaries are not well defined because of inhomogeneity caused by seiching and detrainment (Figures 4-6). The variation in DO around the plume is also substantial, and selection of improper DO boundary conditions may have resulted in the slight underprediction of the DO concentration profile (Figure 13). Using a single profile for the model calculation is therefore not appropriate under such heterogeneous boundary conditions.

[23] Figure 14 shows a sensitivity analysis performed using different boundary profiles along the length of the transect ( $x$ axis indicates distance of boundary profile from plume centerline). As described above, the plume rises higher using profiles closest to the center, as the vertical density structure is more homogeneous. The predicted DMPR deepens sharply with boundary profiles farther than $5 \mathrm{~m}$ from the plume centerline, particularly when using the southerly profiles, the direction from which the seiche current is flowing while the transect was measured. The DMPR tends to stabilize with increasing distance from the diffuser because of the more uniform structure of the vertical profiles.

[24] The ED is calculated by matching the final density of the plume water with the density at depth using the boundary profiles. Variations occur because a small change in the final density of the plume water at the DMPR can result in a substantial difference in the ED in the less stratified bottom water. Also, because the plume encounters a strong temperature gradient as it stops, a small increase in predicted plume rise translates into a relatively large change in the predicted density; that is, the higher the water rises, the less dense it becomes. It is important to note that the ED is based only on a density comparison, and that it assumes no further entrainment as it falls back. The ED predictions are also less variable with increasing distance from the plume, and in reality, probably occur over a vertical zone in the water column because of multiple detrainment, through flow, and entrainment into the fallback water.

\section{Conclusions}

[25] A steady state, horizontally averaged, bubble-plume model was evaluated on a 1:1 scale using high-resolution CTD data collected in Lake Hallwil, Switzerland. Observations of the plume near and far field revealed the following:

[26] 1. The plume-lake interaction was found to be much more complex than previously believed. The bubble plume creates its own local environment on two different scales: the plume torus, where the directly detrained water and fallback water are accumulated over tens of meters off the plume, while the seiche-induced near field of the plume reaches up to $0.5 \mathrm{~km}$ in either direction. This distance is governed by the internal seiche velocities (or other horizontal cross flows) multiplied by one half the seiche period.

[27] 2. The data show that the plume fallback and mixing results in a more homogeneous density structure within the plume torus. This leads to a shallower depth of maximum plume rise (DMPR), as there is less density gradient to overcome. To properly model the plume, it is necessary to select appropriate density boundary conditions.

[28] 3. Using the near-field boundary conditions, rather than the far-field boundary conditions, produced excellent agreement, with a shallower DMPR and closer constituent predictions.

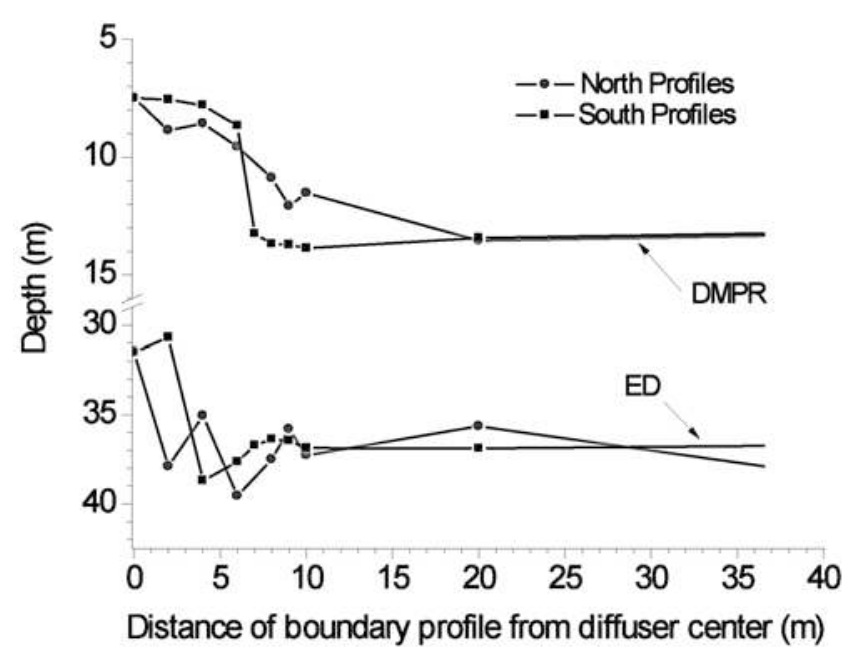

Figure 14. Predicted depth of maximum plume rise (DMPR) and equilibrium depth (ED) as a function of boundary profile distance from diffuser ( $x$ axis indicates profile distance from centerline of a single diffuser). 
[29] 4. Because a significant portion of entrained plume water is from the torus, the plume constituents depend strongly on the near-field environment, which is created by the plume itself. The plume properties and model predictions are strongly dependent on these continually changing boundary conditions.

[30] 5. The data also show that the plume falls back much deeper than expected from the far-field model predictions, which leads to considerable short-circuiting of the return flow and a subsequent reduction in the rate of oxygen transport to the entire lake. It is unclear whether the deeper fallback is primarily due to multiple detrainments or the more isothermal plume torus. This fallback may alter the entrainment coefficient, currently assumed to be constant, due to enhanced turbulence at the plume/ambient water interface.

[31] 6. The bubble core was found not to spread, which requires particular attention to the interpretation of the model as the bubble-plume will in reality rise locally higher than predicted, possibly penetrating into the thermocline or photic zone. This will also increase the likelihood of multiple detrainments, as the positive buoyancy flux imparted by the gas bubbles is not distributed over the plume outer core.

[32] 7. Because the water flowing from the far field to the plume travels along the isopycnals, the altered isotherms in the near field affect where water is withdrawn from the far field into the plume. Furthermore, as the return flow is along the same isopycnals, lateral transport is limited to enhanced horizontal diffusion.

[33] It is evident that a method needs to be developed to predict the altered near-field, short-circuiting, and fallback of detrained plume water past the equilibrium depth. One approach currently being examined is a coupled plumereservoir model using an improved plume model and a twodimensional reservoir model (CE-QUAL-W2) [Cole and Wells, 2000]. This coupled model is currently being developed to predict plume dynamics and the near- and far-field responses. It may, however, require the addition of a plume fallback model to adequately predict the transport of water in the near-field torus. A preliminary version of such a coupled model for a linear (as opposed to circular) bubbleplume has been developed and used to predict the evolving temperature and dissolved oxygen concentrations in a small side-stream reservoir. Once completed, the coupled model will be used to further investigate the plume models (both circular and linear) in full-scale lake or reservoir settings to better understand the plume-lake interaction, plumeenhanced mixing and warming, and other aspects such as variation in entrainment and potential nitrogen supersaturation in the case of air. The validated, coupled plume/ reservoir model should also prove to be a valuable tool to operationally enhance existing systems, to investigate the effectiveness of bubble-plumes in drinking water reservoirs, to perform economic optimizations for proposed or existing installations, and to identify future research needs.

\section{Notation}
A lake area, $\mathrm{m}^{2}$.
b plume radius, $\mathrm{m}$.
C dissolved concentration, $\mathrm{mol} \mathrm{m} \mathrm{m}^{-3}$.
DN dissolved nitrogen, $\mathrm{mol} \mathrm{m}^{-3}$.

DO dissolved oxygen, $\mathrm{mol} \mathrm{m} \mathrm{m}^{-3}$.

$F_{D}$ dissolved gas flux, mol s${ }^{-1}$.

$\mathrm{F}_{\mathrm{G}}$ gas flux, mol s${ }^{-1}$.

Fr Froude number, dimensionless.

$\mathrm{F}_{\mathrm{S}}$ dissolved solids flux, $\mathrm{g} \mathrm{s}^{-1}$.

$\mathrm{F}_{\mathrm{T}}$ temperature flux, ${ }^{\circ} \mathrm{C} \mathrm{m}^{3} \mathrm{~s}^{-\mathrm{i}}$.

$\mathrm{g}$ gravitational acceleration, $\mathrm{m} \mathrm{s}^{-2}$.

$\mathrm{H}$ gas solubility constant, $\mathrm{mol} \mathrm{m}{ }^{-3} \mathrm{bar}^{-1}$.

$\mathrm{k}_{\mathrm{t}}$ apparent vertical turbulent diffusivity, $\mathrm{cm}^{2}$ $\mathrm{s}^{-1}$.

$\mathrm{K}_{\mathrm{L}}$ mass transfer coefficient, $\mathrm{m} \mathrm{s}^{-1}$.

$\mathrm{M}$ plume momentum, $\mathrm{m}^{4} \mathrm{~s}^{-2}$.

$\mathrm{N}$ number flux of bubbles, $\mathrm{s}^{-1}$.

$\mathrm{P}$ pressure, bar.

$\mathrm{Q}_{\mathrm{g}}$ gas flow rate, $\mathrm{Nm}^{3} \mathrm{~h}^{-1}$.

$\mathrm{Q}$ water volume flux, $\mathrm{m}^{3} \mathrm{~s}^{-1}$.

$\mathrm{r}$ bubble radius, $\mathrm{m}$.

$\mathrm{S}$ salinity, $\mathrm{g} \mathrm{kg}^{-1}$.

$\mathrm{t}$ time, $\mathrm{s}$.

$\mathrm{T}$ temperature, ${ }^{\circ} \mathrm{C}$.

$\mathrm{V}_{\mathrm{g}}$ gas holdup, dimensionless.

$\mathrm{v}$ velocity, $\mathrm{m} \mathrm{s}^{-1}$.

$\mathrm{y}$ gas concentration, $\mathrm{mol} \mathrm{m} \mathrm{m}^{-3}$.

$\mathrm{z}$ depth, $\mathrm{m}$.

Greek letters

$\alpha$ entrainment coefficient, dimensionless.

$\lambda$ ratio of bubble-containing region of plume to total plume diameter.

$\rho$ density, $\mathrm{kg} \mathrm{m}^{-3}$.

Subscripts

a ambient water.

b bubble.

i gas species, oxygen or nitrogen.

$\mathrm{p}$ plume water and gas mixture.

w plume water.

Superscript

0 initial condition.

[34] Acknowledgments. The authors thank Manuela Saballus, Michael Schurter, Erwin Schäffer, and Cristian Teodoru for assisting with field data collection. Financial support was provided by the U.S. National Science Foundation (grant BES 0202034) with supplemental funding from the Swiss Federal Institute for Environmental Science and Technology (EAWAG) and Canton Aargau.

\section{References}

Asaeda, T., and J. Imberger (1993), Structure of bubble plumes in linearly stratified environments, J. Fluid Mech., 249, 35-57.

Beutel, M. W., and A. J. Horne (1999), A review of the effects of hypolimnetic oxygenation on lake and reservoir water quality, J. Lake Reservoir Manage., 15(4), 285-297.

Borchers, O., C. Busch, A. Sokolichin, and G. Eigenberger (1999), Applicability of the standard $\mathrm{k}-\varepsilon$ turbulence model to the dynamic simulation of bubble columns. Part II: Comparison of detailed experiments and flow simulations, Chem. Eng. Sci., 54(24), 5927-5935.

Brevik, I., and Ø. Kristiansen (2002), The flow in and around air-bubble plumes, Int. J. Multiphase Flow, 28(4), 617-634.

Burris, V. L., D. F. McGinnis, and J. C. Little (2002), Predicting oxygen transfer rate and water flow rate in airlift aerators, Water Res., 36(18), 4605-4615.

Cole, T. M., and S. A. Wells (2000), CE-QUAL-W2: A two-dimensional, laterally averaged, hydrodynamic and water quality model, version 3.0, Instr. Rep. EL-00-1, U.S. Army Eng. and Res. Dev. Cent., Vicksburg, Miss.

Cooke, G. D., E. B. Welch, S. A. Peterson, and P. R. Newroth (1993), Restoration and Management of Lakes and Reservoirs, 2nd ed., Lewis, Boca Raton, Fla. 
Gächter, R., and B. Müller (2003), Why the phosphorus retention of lakes does not necessarily depend on the oxygen supply to their sediment surface, Limnol. Oceanogr., 48(2), 929-933.

Gwaze, S. (2003), Structure, dynamics and energetics of internal waves in Lake Hallwil, M. Sc., UNESCO-IHE Inst. for Water Educ., Delft, Netherlands.

Johnson, G. P., N. J. Hornewer, D. M. Robertson, D. T. Olson, and J. Gioja (2000), Methodology, data collection, and data analysis for determination of water-mixing patterns induced by aerators and mixers, U.S. Geol. Surv. Water Resour. Invest. Rep., 00-4101.

Lemckert, C. J., and J. Imberger (1993), Energetic bubble plumes in arbitrary stratification, J. Hydraul. Eng., 119(6), 680-703.

McDougall, T. J. (1978), Bubble plumes in stratified environments, J. Fluid Mech., 85, 655-672.

McGinnis, D. F., and J. C. Little (1998), Bubble dynamics and oxygen transfer in a Speece Cone, Water Sci. Technol., 37(2), 285-292.

McGinnis, D. F., and J. C. Little (2002), Predicting diffused-bubble oxygen transfer rate using the discrete-bubble model, Water Res., 36(18), 46274635 .

Mobley, M. H. (1997), TVA reservoir aeration diffuser system, TVA technical paper 97-3 presented at ASCE Waterpower '97, Am. Soc. of Civ. Eng., Atlanta, Ga., 5-8 Aug.

Morton, B. R. (1959), Forced plumes, J. Fluid Mech., 5, 151-163.

Nakamura, Y., and T. Inoue (1996), A theoretical study on operation condition of hypolimnetic aerators, Water Sci. Technol., 34(7-8), $211-218$.

Powell, T., and A. Jassby (1974), The estimation of vertical eddy diffusivities below the thermocline in lakes, Water Resour. Res., 10(2), $191-198$.
Scheidegger, A., A. Stöckli, and A. Wüest (1994), Einfluss der internen Sanierungsmassnahmen auf den Sauerstoffhaushalt im Hallwilersee, Wasser Energ. Luft, 86(5/6), 126-131.

Stöckli, A., and M. Schmid (1987), Die Sanierung des Hallwilersees, Wasser Energ. Luft, 79(7/8), 143-149.

Wehrli, B., and A. Wüest (1996), Zehn Jahre Seenbelüftung: Erfahrungen und Optionen, EAWAG Rep. 9, Swiss Fed. Inst. for Environ. Sci. and Technol., Katanienbaum, Switzerland.

Wu, R. S. S., B. S. Zhou, D. J. Randall, N. Y. S. Woo, and P. K. S. Lam (2003), Aquatic hypoxia is an endocrine disruptor and impairs fish reproduction, Environ. Sci. Technol., 37(6), 1137-1141.

Wüest, A., and A. Lorke (2003), Small-scale hydrodynamics in lakes, Annu. Rev. Fluid Mech., 35, 373-412.

Wüest, A., N. H. Brooks, and D. M. Imboden (1992), Bubble plume modeling for lake restoration, Water Resour. Res., 28(12), 3235-3250.

Wüest, A., G. Piepke, and D. C. Van Senden (2000), Turbulent kinetic energy balance as a tool for estimating vertical diffusivity in wind-forced stratified waters, Limnol. Oceanogr., 45(6), 1388-1400.

J. C. Little, Department of Civil and Environmental Engineering, Virginia Polytechnic Institute and State University, Blacksburg, VA 240610246, USA. (jcl@vt.edu)

A. Lorke, D. F. McGinnis, and A. Wüest, Applied Aquatic Ecology, Swiss Federal Institute for Environmental Science and Technology (EAWAG), Kastanienbaum, CH-6047, Switzerland.

A. Stöckli, Baudepartement des Kantons Aargau, Abteilung für Umwelt, CH-5001 Aarau, Switzerland. 